\title{
Using UAS Capabilities To Help Identify Hummock-Hollow Formation and Fragmentation in Critical Marsh Habitat (Spartina patens) for Mottled Ducks in Southeast Texas
}

Open-File Report 2019-1045 



\section{Using UAS Capabilities To Help Identify Hummock-Hollow Formation and Fragmentation in Critical Marsh Habitat (Spartina patens) for Mottled Ducks in Southeast Texas}

By William R. Jones, Stephen B. Hartley, Camille L. Stagg, and Michael J. Osland

Open-File Report 2019-1045 


\title{
U.S. Department of the Interior DAVID BERNHARDT, Secretary
}

\author{
U.S. Geological Survey \\ James F. Reilly II, Director
}

U.S. Geological Survey, Reston, Virginia: 2019

For more information on the USGS - the Federal source for science about the Earth, its natural and living resources, natural hazards, and the environment-visit https://www.usgs.gov or call 1-888-ASK-USGS.

For an overview of USGS information products, including maps, imagery, and publications, visit https://store.usgs.gov.

Any use of trade, firm, or product names is for descriptive purposes only and does not imply endorsement by the U.S. Government.

Although this information product, for the most part, is in the public domain, it also may contain copyrighted materials as noted in the text. Permission to reproduce copyrighted items must be secured from the copyright owner.

Suggested citation:

Jones, W.R., Hartley, S.B., Stagg, C.L., and Osland, M.J., 2019, Using UAS capabilities to help identify hummockhollow formation and fragmentation in critical marsh habitat (Spartina patens) for mottled ducks in southeast Texas: U.S. Geological Survey Open-File Report 2019-1045, 6 p., https://doi.org/10.3133/ofr20191045.

ISSN 2331-1258 (online) 


\section{Acknowledgments}

We would like to thank Jena Moon, Stephanie Goehring, and Douglas Head with McFaddin National Wildlife Refuge for their hard work and assistance in the field. We thank J.D. Murphree Wildlife Management Area for authorizing our research on the property and Laura Feher, whose field work and surveying expertise helped with the image accuracy and photogrammetry production. 


\section{Contents}

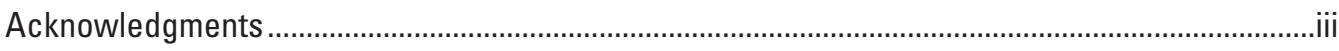

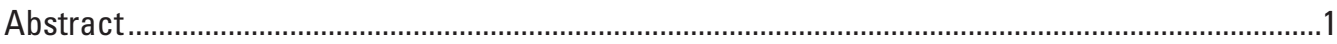

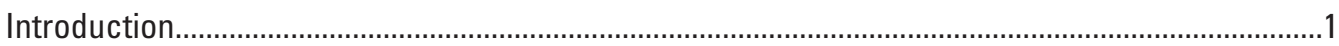

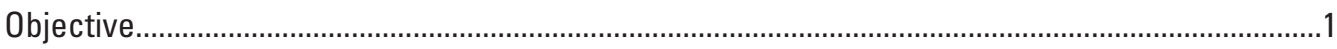

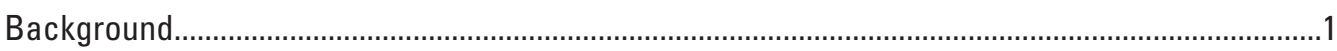

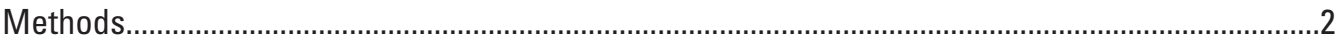

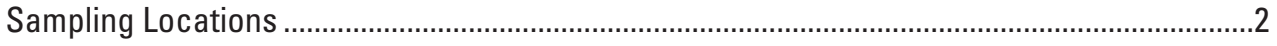

Ground Control Points ...........................................................................................................

Data Acquisition and Postprocessing ...................................................................................

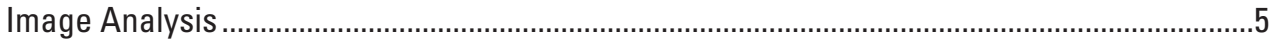

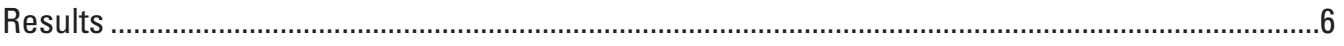

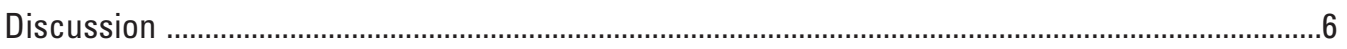

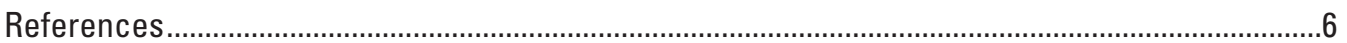

\section{Figures}

1. A, Esri background image with study area sites on McFaddin National Wildlife Refuge, Texas, and $B$, map of the study area location on Esri light grey canvas.

2. Drone aerial imagery with ground control points strategically placed near each corner of study site....

3. Natural color orthomosaic of imagery collected with unmanned aerial system and digital single lens camera of $A$, site D1 and $B$, site D2

4. $A$, Final natural color orthomosaic of imagery clipped to project boundary and $B$, final classified imagery

\section{Tables}

1. Land-water acreage classification results for all six study sites on McFaddin National Wildlife Refuge, Texas 


\section{Conversion Factors}

U.S. customary units to International System of Units

\begin{tabular}{|c|c|c|}
\hline Multiply & By & To obtain \\
\hline \multicolumn{3}{|c|}{ Length } \\
\hline inch (in.) & 2.54 & centimeter $(\mathrm{cm})$ \\
\hline inch (in.) & 25.4 & millimeter (mm) \\
\hline foot $(\mathrm{ft})$ & 0.3048 & meter $(\mathrm{m})$ \\
\hline \multicolumn{3}{|c|}{ Area } \\
\hline acre & 4,047 & square meter $\left(\mathrm{m}^{2}\right)$ \\
\hline acre & 0.4047 & hectare (ha) \\
\hline acre & 0.4047 & square hectometer $\left(\mathrm{hm}^{2}\right)$ \\
\hline acre & 0.004047 & square kilometer $\left(\mathrm{km}^{2}\right)$ \\
\hline
\end{tabular}

International System of Units to U.S. customary units

\begin{tabular}{lll}
\hline \multicolumn{1}{c}{ Multiply } & By & \multicolumn{1}{c}{ To obtain } \\
\hline millimeter $(\mathrm{mm})$ & Length & \\
meter $(\mathrm{m})$ & 0.03937 & inch (in.) \\
meter $(\mathrm{m})$ & 3.281 & foot (ft) \\
\hline & 1.094 & yard (yd) \\
\hline square meter $\left(\mathrm{m}^{2}\right)$ & Area & acre \\
\hline
\end{tabular}





\title{
Using UAS Capabilities To Help Identify Hummock-Hollow Formation and Fragmentation in Critical Marsh Habitat (Spartina patens) for Mottled Ducks in Southeast Texas
}

\author{
By William R. Jones, Stephen B. Hartley, Camille L. Stagg, and Michael J. Osland
}

\section{Abstract}

For many years, marshes in the coastal areas from Texas to Louisiana have served as critical habitat for Anas fulvigula, the mottled duck. Mottled ducks are a priority species in the Texas/Louisiana Gulf Coast area and have been affected by critical habitat reduction. In recent years, mottled duck habitats have been threatened by natural and anthropogenic changes including urbanization, flooding, saltwater intrusion, and hydrologic alterations. These impacts are affecting the quality of habitat that is essential for the mottled duck nesting, feeding, and livelihood. Cumulative and synergistic effects of contamination and invasive species encroachment have also caused mottled duck habitat to be considered as some of the most critically endangered habitats in the United States. To help understand the environmental conditions that characterize the coastal landscape, U.S. Geological Survey researchers used an unmanned aerial system (UAS) to acquire high-resolution imagery to document current land and water spatial configuration and wetland health at McFaddin National Wildlife Refuge, Texas.

\section{Introduction}

The unmanned aerial system (UAS) is an increasingly used tool for environmental assessment and monitoring changing landscapes. These systems offer a cost-effective means to collect high-resolution spatial and temporal data in a short amount of time. The ability of a UAS to fly at low altitudes with multiple acquisition sensors allows greater flexibility for scientific research. The improved UAS usability for data acquisition decreases the need to outsource costly aerial missions, and the high-resolution data can be easily incorporated into field-based investigations. In this project, U.S. Geological Survey (USGS) researchers acquired, mosaicked, and classified high-resolution imagery collected with a UAS to illustrate progressive marsh fragmentation and degradation of critical habitat (specifically, Spartina patens) for Anas fulvigula (mottled ducks) at McFaddin National Wildlife Refuge, Texas.

\section{Objective}

The objective of this study was to use UAS technology to provide a spatial component in the form of aerial imagery to correlate ground observations to quantify marsh fragmentation and thus wetland degradation. Fragmentation was quantified on the basis of the amount and proximity of land and water pixels in the imagery. Imagery data will be correlated with other field-based abiotic and biotic data to better understand the mechanisms of marsh degradation. These data will also serve as a baseline dataset for comparisons of any future data collection.

\section{Background}

This project was part of a larger ongoing project conducted by USGS researchers to identify hydrologic controls on coastal Spartina patens marshes and optimal hydrological conditions for sustainable mottled duck habitat. To assist with this larger project, researchers used the UAS to collect spatial data in the form of high-resolution imagery. This imagery was classified into two categories: (1) land (hummock) - any vegetation and (2) water (hollow) - any nonvegetation features, such as open water or unvegetated sediment. The total areal cover of land versus water and the spatial configuration of the land and water pixels in the imagery were used to characterize the health of the wetland sites and the processes of land loss. Wetland loss occurs through progressive fragmentation, or increasing conversion of land to open water, which ultimately leads to habitat loss. The UAS image classification data were used in concert with field-based ground survey data (elevation, inundation vegetation cover, and vegetation height) to identify mechanisms of marsh degradation. The data quantify not only the total area 
of land and water coverage but also the spatial configuration of the land and water pixels. The spatial configuration can have important implications for the functioning and health of the system. For example, a wetland area where most of the land pixels are aggregated would represent a healthy marsh, whereas an area where the land pixels are completely disaggregated, or scattered, would represent a degraded marsh (Couvillion and others, 2016).

Given current global climate change indicators and sea-level rise projections for the Texas Chenier Plain region, mottled ducks are poised to lose greater than 50 percent of their preferred habitat over the next century (Moon, 2014). This UAS project identifies the conditions of healthy marsh habitat for mottled ducks and the conditions leading to habitat degradation. This information can be used to help counter the effects of marsh degradation to improve habitat conditions for mottled ducks and ultimately may help to increase the regional population size of the species.

$\boldsymbol{A}$

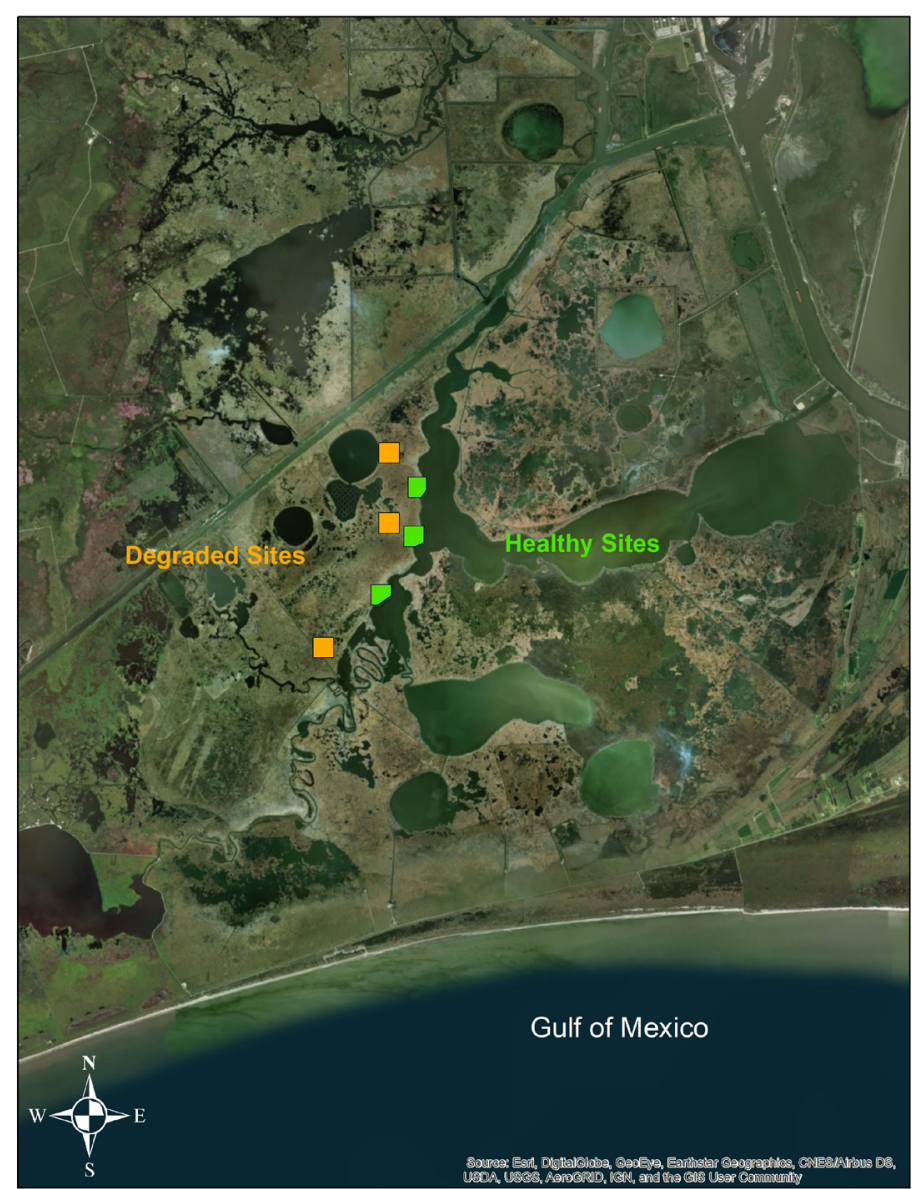

\section{Methods}

\section{Sampling Locations}

This study was conducted in Chenier Plain coastal wetlands dominated by Spartina patens, a brackish marsh species, on McFaddin National Wildlife Refuge in southeast Texas (fig. 1). A total of six sites were selected (three healthy sites and three degraded sites) and flown with a UAS to acquire high-resolution imagery. A sampling station was located at the center of each site, and this center point was used to create a 40-acre (16-hectare) boundary for the imagery collection. The three healthy sites were located along the shoreline, and the project boundary extends over open water. For this reason, healthy site boundaries were modified in size to minimize flying time over open water, which can be a flying hazard.

\section{B}

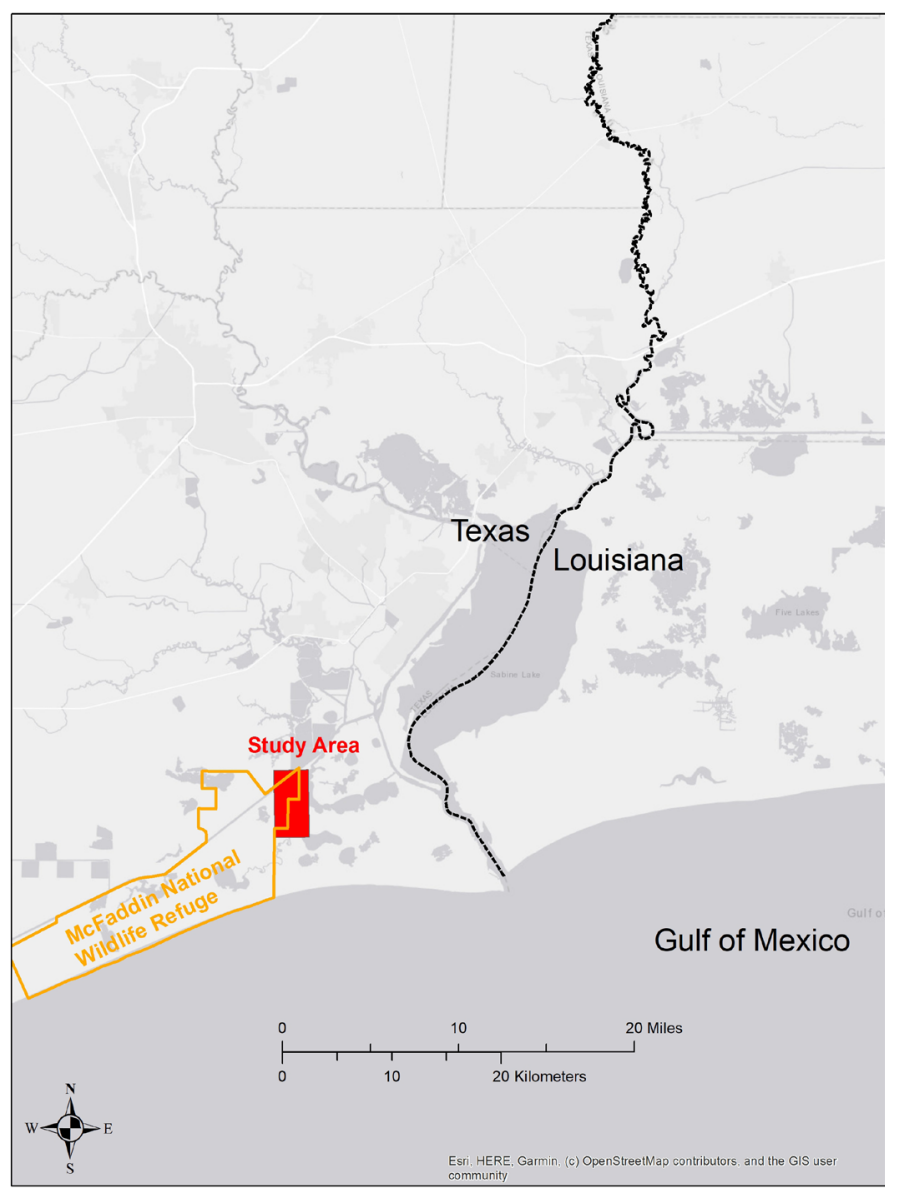

Figure 1. A, Esri background image with study area sites on McFaddin National Wildlife Refuge, Texas, and $B$, map of the study area location on Esri light grey canvas. 


\section{Ground Control Points}

Because of the lack of identifiable features and the homogeneous nature of the landscape, ground control points (GCPs) were used to accurately position imagery on the Earth's surface (fig. 2). Each of the six study sites has a center control marker that is used for ground sampling analysis. These center control markers in addition to four additional GCPs were used to correctly register the imagery to the Earth's surface. These four additional GCPs were established near each of the four corners of each study site, thus assuring evenly spaced GCPs. Control points are made from 5-foot-long and 4-inch-wide polyvinyl chloride (PVC) pipes. Each PVC pipe was driven 2 feet into the ground, leaving 3 feet exposed for identification in the imagery. To better identify each PVC pipe in the imagery, white caps were placed on the ends for better visual identity. Using real time kinematic (RTK) survey equipment, each GCP was surveyed to obtain accurate coordinates and elevation to apply to the image rectification.

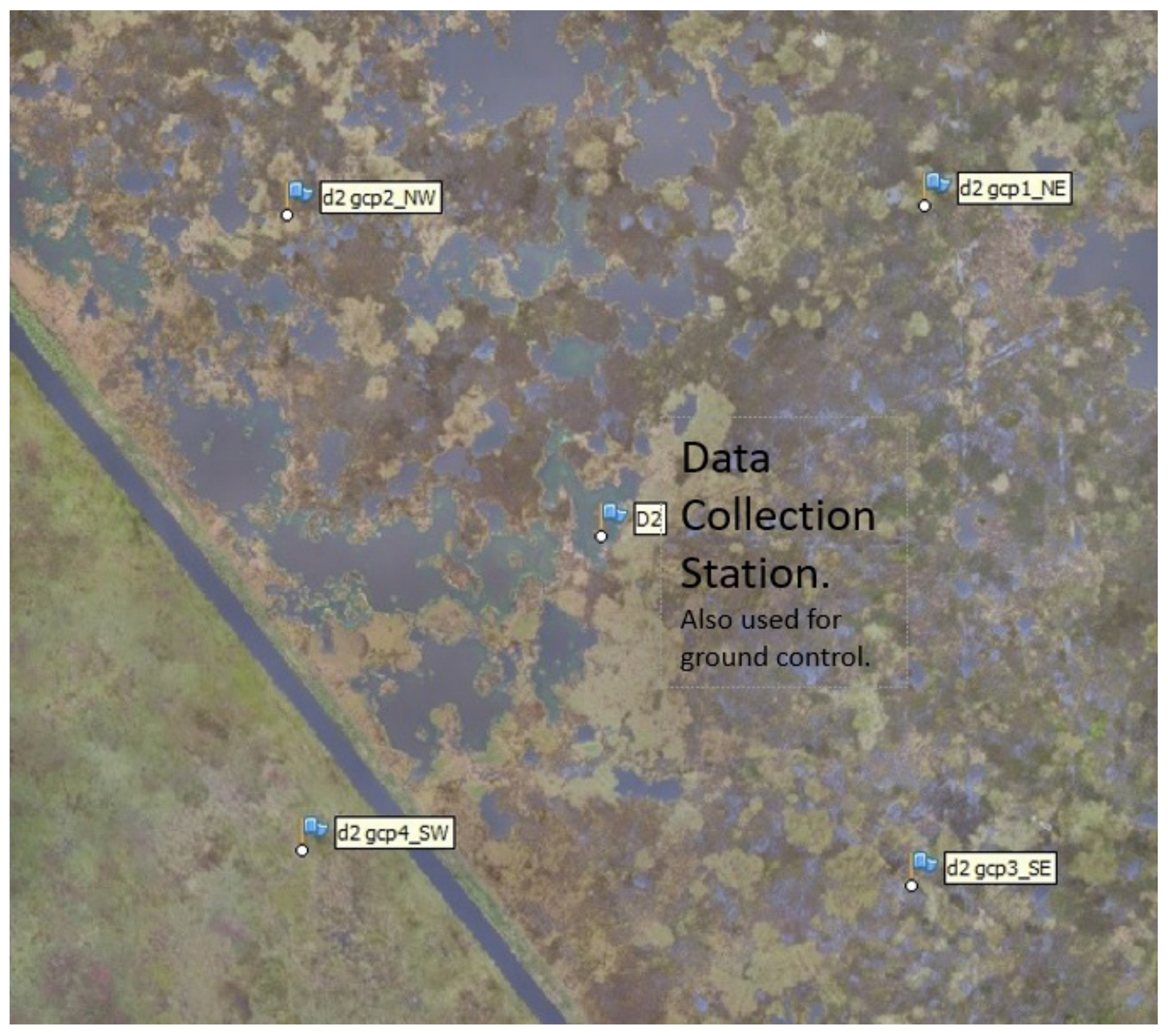

Figure 2. Drone aerial imagery with ground control points strategically placed near each corner of study site. 


\section{Data Acquisition and Postprocessing}

Data acquisition utilized the 3DR Solo UAS (3D

Robotics, Inc.) to fly this mission. The 3DR Solo is a quadcopter that is designed to carry a single sensor/camera to capture remotely sensed data. Using "Mission Planner" flight planning software (ArduPilot), automated flight plans were developed for each of the six study sites. For continuous and complete coverage, a crosshatch-pattern flight plan was created with a 60 percent end lap and 60 percent side lap to reduce the event of any holidays (missing imagery coverage).
The altitude for this mission was 350 feet, resulting in a ground sample distance (GSD) of 1.18 inches ( 0.03 meters). To acquire the imagery, the Ricoh GR II digital single lens camera (Ricoh Imaging Company, Ltd.) was used to capture individual frames (5-second interval) for each of the six study sites. These frames were used to create a seamless orthomosaic (fig. 3), which was then classified into land and water categories. The orthomosaic of each study site was created from the red, green, and blue visible light spectrum (natural color). Agisoft PhotoScan software (Agisoft LLC) was used to perform photogrammetric processing of the digital images.

\section{A}

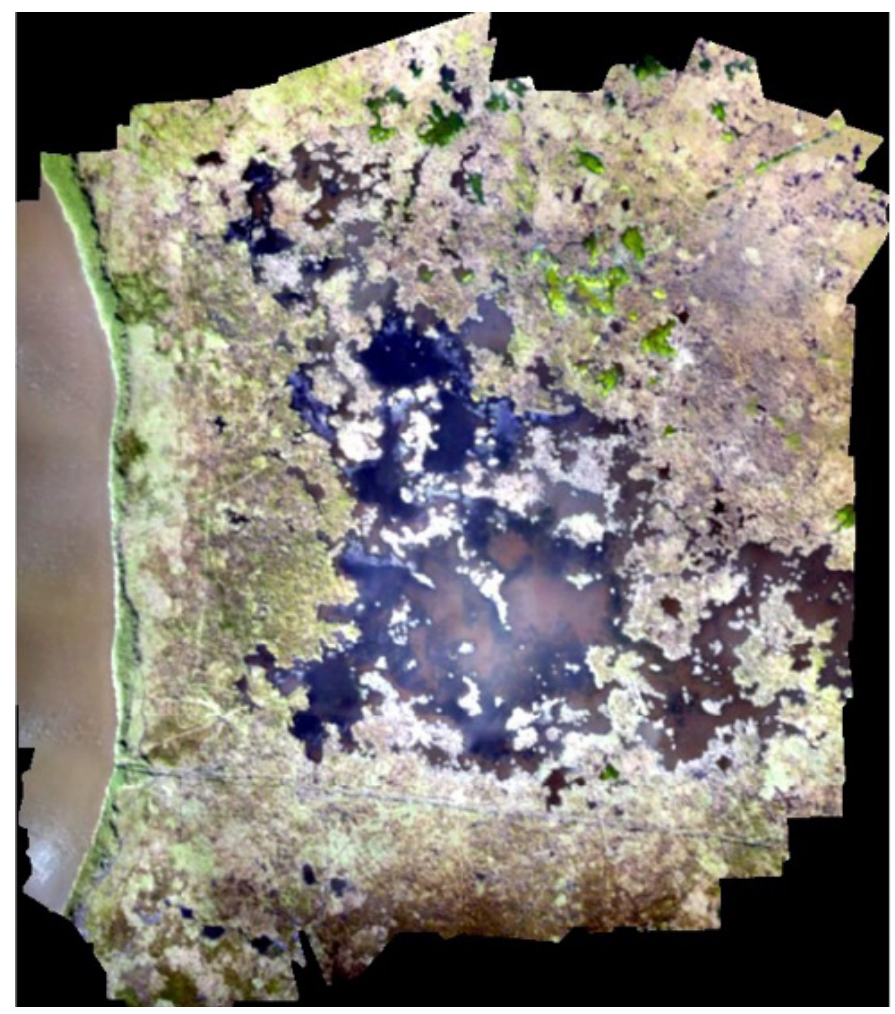

B

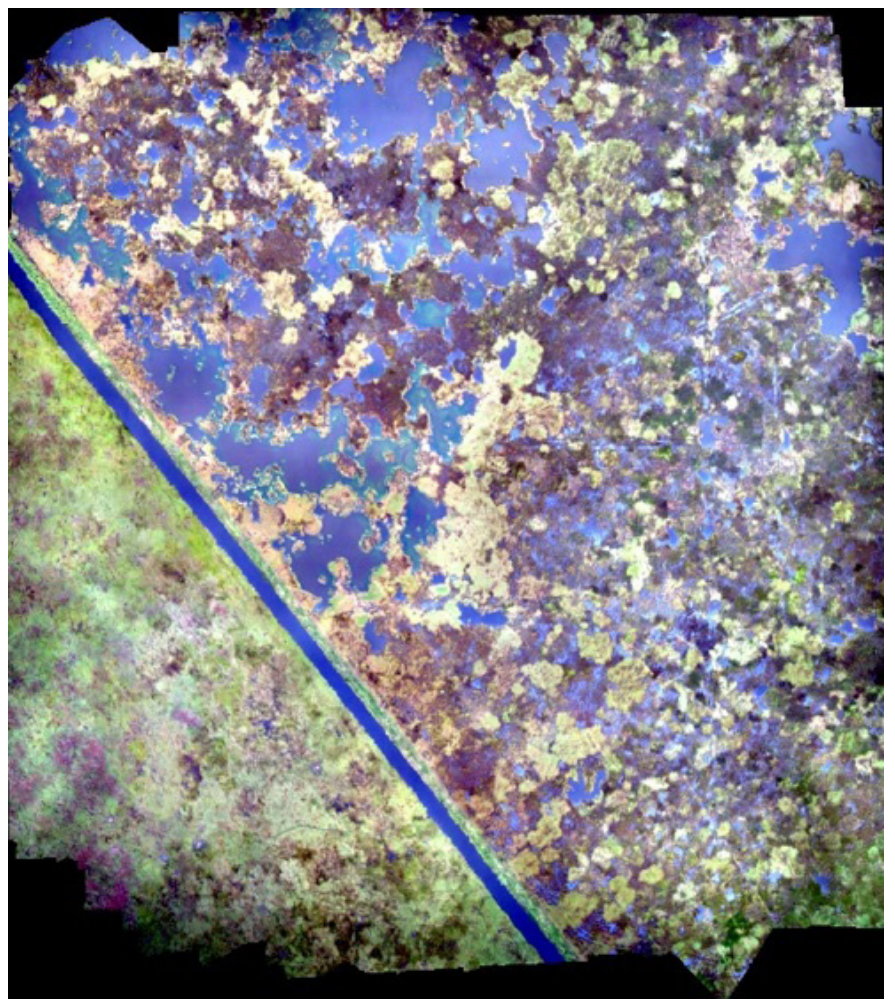

Figure 3. Natural color orthomosaic of imagery collected with unmanned aerial system (UAS) and digital single lens camera of $A$, site $\mathrm{D} 1$ and $B$, site $\mathrm{D} 2$. 


\section{Image Analysis}

The land-water classification was derived from the natural color imagery acquired from the 3DR Solo with attached Ricoh GR II camera. The classification was performed in Erdas Imagine software (Hexagon Geospatial), which is designed to process and analyze geospatial data. An unsupervised classification was performed to group pixels together on the basis of their spectral similarity. The unsupervised classification is an automated process where the user has some control over the inputs. These inputs include number of classes, the maximum iterations (which is how many times the classification algorithm runs), and the threshold percent, which determines when to end the classification procedure. For this classification, the number of classes input was set to 75 , maximum iterations input was set to 50, and threshold input was set to 0.96 percent. After the automated classification was complete, each class was interpreted and grouped into either land or water categories. All areas characterized by emergent vegetation, wetland forest, scrub-shrub, or uplands were classified as land, whereas open water, aquatics, and unvegetated sediment were classified as water. After each of the 75 classes was grouped into land or water, the file was recoded down to just two categories, land and water. At this point, the file was then manually edited to correct any misclassified pixels. Where difficulties arose in identifying vegetation, ancillary datasets were used to help classify the data. To maintain editing consistency, manual editing was limited to 8 hours per study site.

Normally, Spartina patens vegetation does not cause issues with classification, but because of the high resolution of the imagery (1.18 inches/ 0.03 meters) there will be inherent "noise" that causes speckling throughout the classified image. With the image resolution at such a small GSD, the smallest of information will be visible. These small pixels of information that we call "noise" were introduced into our image classification, mostly from vegetation shadows. To reduce the noise and maintain confidence regarding the land and water classification, we defined a threshold of 69 pixels so that any cluster smaller than 69 pixels was absorbed into the surrounding classification category (fig. 4). The threshold size of 69 pixels $(0.25$ meter $\times 0.25$ meter $=0.0625$ square meter $)$ was selected because it represents the field definition of habitat (Hummock/ Hollow) that can be classified with a degree of confidence. In this study, we attempted to identify hollows, which are low areas or holes in the vegetation that may suggest a degradation of adjacent marsh. For our field study analysis, a hollow is defined as an area of water that is 0.25 meter $\times 0.25$ meter $=0.0625$ square meter ( 69 pixels) or greater. Any cluster of cells smaller than 69 pixels was absorbed into the surrounding habitat type. This method helped reduce noise and maintain confidence in the hollow identification.

\section{A}

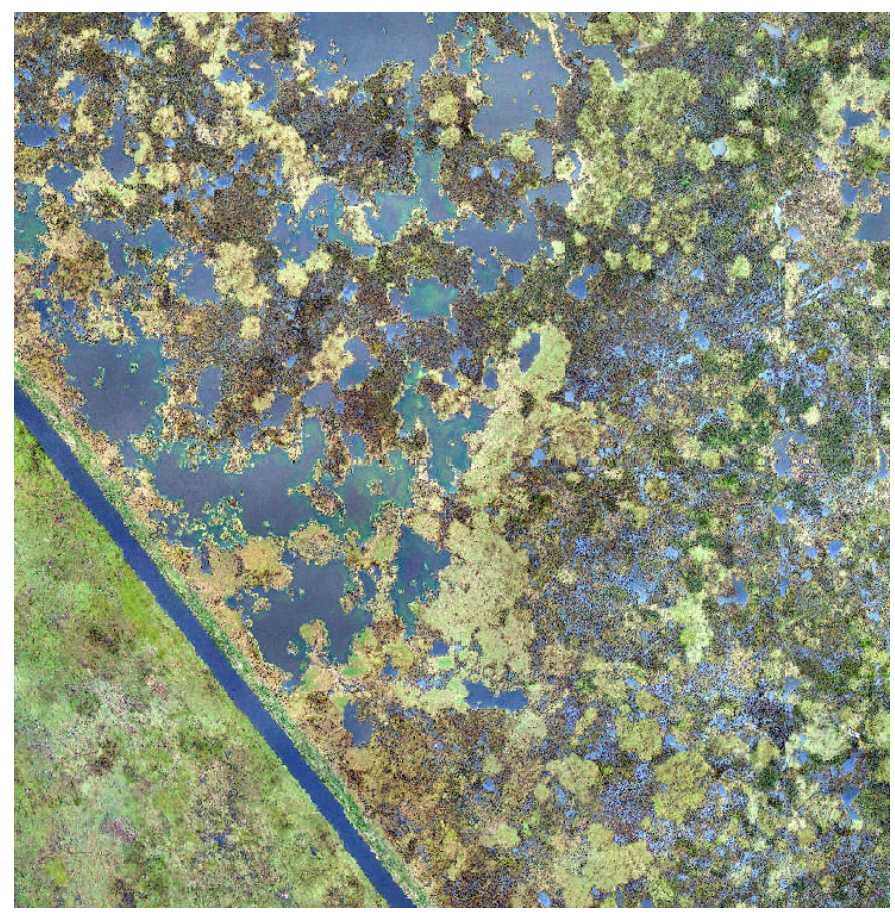

B

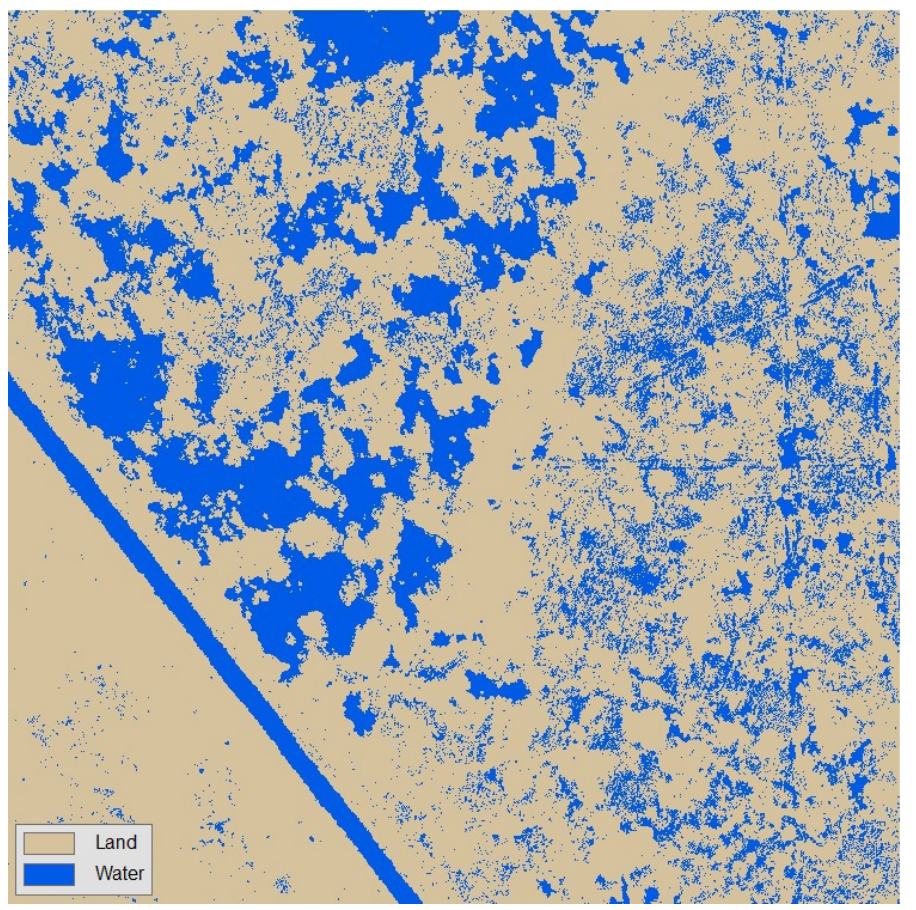

Figure 4. $A$, Final natural color orthomosaic of imagery clipped to project boundary and $B$, final classified imagery. 


\section{Results}

After setting our minimum mapping unit ( 0.25 meter $\times 0.25$ meter $=0.0625$ square meter) of 69 pixels and performing 8 hours of manual editing, final acreage figures were calculated (table 1).

Table 1. Land-water acreage classification results for all six study sites on McFaddin National Wildlife Refuge, Texas.

$[\mathrm{H}$, heathy marsh; $\mathrm{D}$, degraded marsh $]$

\begin{tabular}{lcccccc}
\hline & $\begin{array}{c}\text { H1 } \\
\text { (acres) }\end{array}$ & $\begin{array}{c}\text { H2 } \\
\text { (acres) }\end{array}$ & $\begin{array}{c}\text { H3 } \\
\text { (acres) }\end{array}$ & $\begin{array}{c}\text { D1 } \\
\text { (acres) }\end{array}$ & $\begin{array}{c}\text { D2 } \\
\text { (acres) }\end{array}$ & $\begin{array}{c}\text { D3 } \\
\text { (acres) }\end{array}$ \\
\hline Land & 30.2 & 24.7 & 26.3 & 22.0 & 29.0 & 30.0 \\
Water & 7.4 & 8.5 & 8.0 & 18.0 & 11.0 & 10.0 \\
Total & 37.6 & 33.2 & 34.3 & 40.0 & 40.0 & 40.0 \\
\hline
\end{tabular}

For more information about this publication, contact

Director, Wetland and Aquatic Research Center

U.S. Geological Survey

700 Cajundome Blvd.

Lafayette, Louisiana 70506

For additional information, visit

https://www.usgs.gov/centers/wetland-and-aquatic-research-center-warc

Publishing support provided by

Lafayette Publishing Service Center

\section{Discussion}

For this mission the Ricoh GR II was used to collect the imagery for all six selected sites. The Ricoh collects three-band imagery (red, green, and blue), which produces a natural color product. Although the resolution (0.03 meters) was excellent for identifying homogeneous features, future data acquisitions may be better served with the use of a multispectral camera to improve the classification of mixed vegetation classes. The use of a multispectral camera offers additional bands (red edge and near infrared) that are suited for vegetation analysis. The option of the five bands can help separate vegetation where water, saturated soil, mudflats, and vegetation exist in mixed habitat areas. The dataset generated in this study will serve as a baseline for any future data collections.

\section{References}

Moon, J.A., 2014, Mottled duck (Anas fulvigula) ecology in the Texas Chenier Plain region: Nacogdoches, Tex., Stephen F. Austin State University, dissertation. 
